\title{
Discussion of Design Principles for Water Seal Liquid Separation Tank in Flare System for VOCs Burning
}

\author{
Youping Shou* and Xin Li \\ Key Laboratory of Environmental Protection in Water Transport Engineering Ministry of Communications, Tianjin Research Institute for \\ Water Transport Engineering, 300456Tianjin, P.R. China
}

\begin{abstract}
In the energy and petrochemical industry, the use of the flare to burning VOCs is a conventional approach for port energy storage tanks. This paper briefly introduces the main process of flare system, elaborated with emphasis the water seal liquid tank design. In the water seal liquid tank design combined with practical engineering experience, it provided application and illustrated a number of practical experiences. It also analysis the field should pay attention in practical application process by comprehensive comparison of the data and processes dismantling.
\end{abstract}

\section{Introduction}

In order to ensure safe discharge of normal production and emergency, the port enterprises pay special attention in atmospheric environment protection in port operations. Currently, large-scale petrochemical production enterprises and storage companies are generally required to set up a torch of combustible VOCs. In these conservation devices, flare system is commonly used. In a conventional flare system design, it usually needs to set sub tank and water sealing. The former can ensure the effective separation of particles in the exhaust VOCs in the liquid phase. By the latter to provide the necessary seal VOCs emissions, it improved the flare VOCs emissions safety. Meanwhile, in domestic VOCs chemical elevated flare design, in view of the higher water vapour content of the exhaust gas $(50 \%)$, heavy hydrocarbon component content less features for both project economics and ensure the safety of flare gas emissions. For the demonstration, in the first time using a catchment tank sealing and dispensing functions in one sub-tank seal structure, while reducing design costs and user maintenance costs. It can also reduce the floor space for harbour congestion situations. After driving operation, the results showed that good performance, and it has a wide significance for similar projects [1].

Typically, the seal liquid separation tank in flare system is an important application of petrochemical and LNG/LPG storage tanks for atmospheric environmental protection. The escape of VOCs is an important aspect of air pollution in harbour operation. A coal chemical synthesis VOCs flare overhead means required to deal with the normal operation of the exhaust gas and the gas discharge means accident. Synthesis VOCs flare combustion exhaust gas emissions from a variety of facilities to meet the safety conditions. It was ensuring heat radiation intensity on the ground, and the ground concentrations of harmful residues of combustion while it can meet the national environmental protection requirements [2]. However, operating parameters, configuration parameters, control systems and debugging in design or manufacturing processes are very important parts of the device.

\section{The design principle for seal liquid separation tank}

\subsection{The description of flare system}

The flare system consists of the main torch head and acidic flare tip, molecular seal, seal liquid separation tank, flare tower, fuel gas line, nitrogen line, instrument air lines, fresh water pipeline, ignition control system components [3]. Elevated flare basic flow chart was shown in Figure 1.

The flare system functions and processes of major equipment: by the main torch discharge, the air goes through the main channel into the tank seal points. After the seal segment and sub-segment liquid into the main torch cylinder, and then, it go through molecular seal. Finally, it was discharged from the main torch head combustion [4]. The acidic discharge goes directly into the air through the flame arrester acidic burning torch head. Meanwhile, the fresh water into the tank seal points was pay. After dispensing of accumulated sewage, the air contained VOCs go through the sewage discharge pipe. Meanwhile, the low pressure steam in water seal tank and molecular seal points conduct heat was tracing to prevent freezing at low temperatures by blocking the pipeline. On the one hand, the role of nitrogen molecules to provide the required sealing gas seal, on the other hand, to provide purge the VOCs exhaust gas emissions after stop. The role of the ignition control system is to achieve ignition and flame ground pass aerial ignition. To ensure long light, the torch head can continue to work as well as control access to the water seal liquid separation tank [5]. 


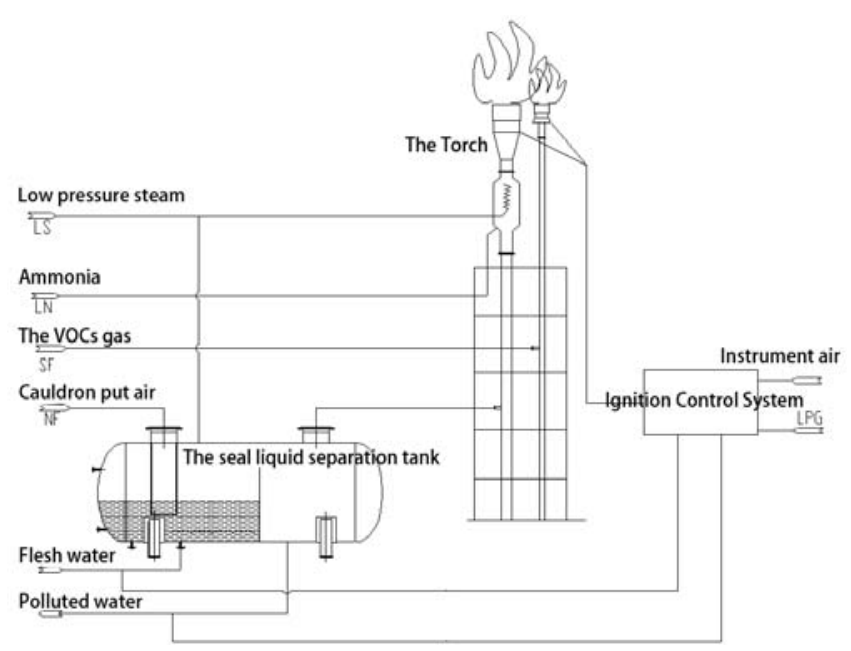

Figure 1. The elevated flare basic flowchart for combustion.

\subsection{The working principle for seal liquid separation tank}

The seal liquid separation tank has two functions. For both sealing and dispensing water tank, by consists of two parts, it had a left seal section and the right to dispense segment. The structure of application and subtank, water sealing are provided. The exhaust VOCs after dispensing the first seal of conventional design compared to its advantages with more suitable for this type of coal chemical torch (due to the high water vapours content, heavy hydrocarbon components less, no set of necessary sub tank). And then, after a complete seal segment dispensing segment. It could largely exhaust gas conditions to win the title carried by the water droplets separated sufficiently effective to improve the flare gas security emissions [6]. A common seal liquid separation tank device is shown in Figure 2.

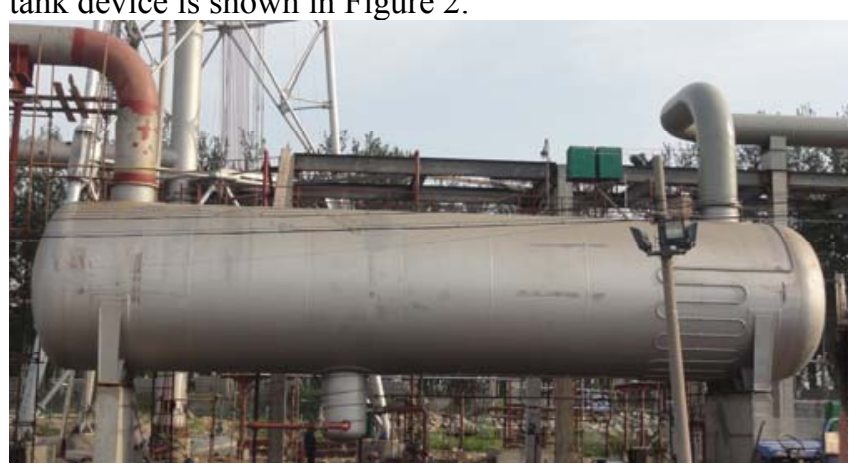

Figure 2. A common seal liquid separation tank device.

In liquid separation section, the exhaust VOCs flow rate go into the dispensing segment decreased. However, the entrained liquid droplets and solid impurities fall due to gravity. It was deposited on the bottom for recycling. Liquid separation section can be separated more than $300 \mu \mathrm{m}$ solid or liquid [7].

In the seal segment as well as the water-sealed tank, the seal segments flare system pressure control device is both flare system security isolation and anti-tempering equipment. Flare systems and devices discharge manifold effectively isolated to prevent air from entering standby when the discharge piping to form a flammable explosive gas [8].

The structure design for the seal liquid separation tank was shown in Figure 3. H nozzle in fresh water through the spout into the seal section, it can stop water when the water level reached a high point. The main torch discharge air through the mouth into the water seal segment $\mathrm{c} 1$ nozzle, it put the air outlet seal section below the surface. All this applications was order to maintain the water seal effect. While it put seal out air from flowing through the dispensing segment, the segment dispensing droplets condense to produce condensate collection tank E nozzle when the condensate drain height of $1.5 \mathrm{~m}$ start and stop the drain below $0.8 \mathrm{~m}$. It can put the air after separation was by c2 discharge port, complete action seal and liquid separation.

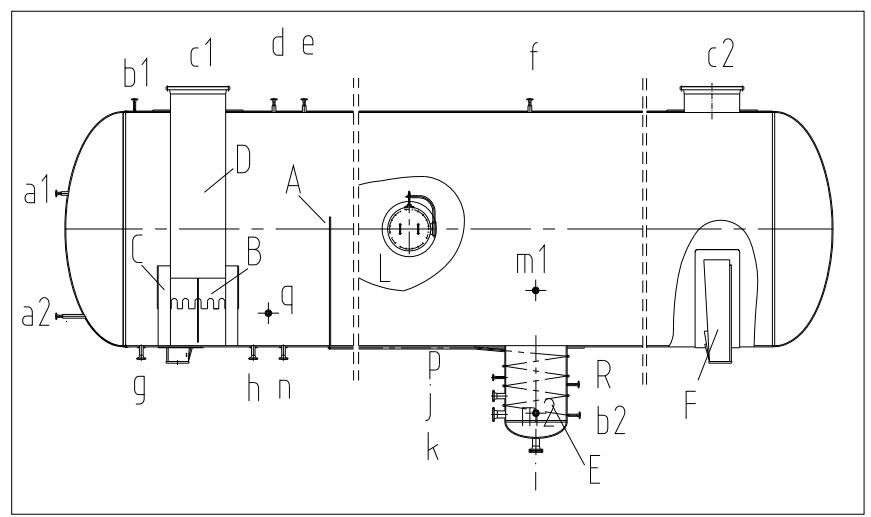

Figure 3. Structure drawings for the seal liquid separation tank.

\subsection{Structure design for the seal liquid separation tank}

Seal liquid separation tank is key equipment. It has two parts: the main seal segment and sub-segment liquid composition. As shown in Figure 3, the seal segment level meter set between a1, a2 nozzle; set between $\mathrm{m} 1$, $\mathrm{m} 2$ condensate segment level meter; $\mathrm{c} 1$ air inlet port to the discharge, and $\mathrm{c} 2$ port of discharge air outlet. $\mathrm{A}$ is retaining fluid seal segment plate for blocking the water into the condensate water seal bag section E; B is damping ring for stabilizing the discharge air emissions; $\mathrm{F}$ is saddle supports; Usually the inlet end of the fixed bearing, the outlet end of the sliding bearings; $\mathrm{E}$ is the condensate package for collecting the separated liquid; into the tank body overhaul $\mathrm{L}$ manholes for maintenance. Commonly, the seal section and condensate section package plus heating pipe to ensure the liquid does not freeze. These structure design principles for the seal liquid separation tank was by many years of practical engineering and debug experience. At the same time, these processes are also carried out in strict accordance with the relevant national standards in designing. 


\section{Calculation for main parameters}

\subsection{The design parameters}

Configuration parameters and process parameters in the device design and manufacture is the main event. Firstly, it can determine the volume flow rate of air discharge and put the maximum amount of physical and chemical properties of air. In the actual design process, in determining the flow rate, according to the relevant specifications to determine the form of the tank and the main dimensions. According to the relevant specifications: diameter liquid separation section is generally the length of $1 / 2-1 / 3$, and $3-4$ times the diameter of the torch; when dispensing segment diameter greater than $1.5 \mathrm{~m}$, the diameter of the liquid collection bag is generally no more than dispensing section one third of the diameter; horizontal plate with retaining liquid water sealing diameter of not less than $3 \mathrm{~m}$; the top stopper plate should be higher than the water level and the difference was $200 \mathrm{~mm}$; retaining fluid plate side gas passage area should be larger than the cross-sectional area of the intake port; heating steam shall ensure that the amount of condensate and water as a liquid seal [9].

According to the nature of the discharge air, it can firstly determine the selection of sub-horizontal seal tank. And then, by the following calculations, a related specification according to design horizontal tank was well done.

In the beginning, the diameter of the seal liquid separation tank import and export was determined which determined by the diameter of the main channel. It was determined by liquid separation section diameter $\mathrm{D}_{1}$ or $\mathrm{D}_{11}$ diameter seal segment according to known discharge air parameters; because of the two results, it is actually a value, so take it greater by the follows [10].

$$
D_{1}=1.15 \times 10^{-2} \sqrt{\frac{Q \times T}{K_{1} \times p \times V_{d}}}
$$

$Q$ : flare gas volume flow, $\mathrm{Nm}^{3} / \mathrm{h}$; according to the maximum value of emissions;

$T$ : gas temperature operating conditions, $\mathrm{K}$;

$K_{1}$ : coefficient, generally ranging from 2.5-3;

Gas pressure P: operating conditions, $\mathrm{KPa}$;

$V_{\mathrm{d}}$ : droplet settling velocity, $\mathrm{m} / \mathrm{s}$, itcan be calculated as follows:

$$
V_{d}=\sqrt{\frac{4 \times g \times\left(\rho_{1}-\rho_{2}\right)}{3 \times \rho_{2} \times C}}
$$

$\mathrm{g}$ : the acceleration of gravity, $9.81 \mathrm{~m} / \mathrm{s}^{2}$;

$\rho 1$ : liquid density, $\mathrm{kg} / \mathrm{m}^{3}$;

$\rho 2$ : gas density, $\mathrm{kg} / \mathrm{m}^{3}$;

$\mathrm{C}$ : droplets in the gas drag coefficient, calculated as follows:

$$
C=\frac{1.307 \times 10^{7} \times d_{1}^{3} \times \rho_{2} \times\left(\rho_{1}-\rho_{2}\right)}{\mu^{2}}
$$

$\mu$ : gas dynamic viscosity, $\mathrm{mPa} \cdot \mathrm{s}$;

$d_{1}$ : droplet diameter, $\mathrm{m}$.
Liquid separation section diameter $\mathrm{D}_{1}$ is determined later, and then determines the length $\mathrm{L}_{1}$ and dispensing liquid collection bag diameter $\mathrm{D}_{2} . \mathrm{L}_{1}$ in accordance with the relevant provisions generally take $2.5-3$ times the $D_{1}$, $\mathrm{D}_{2}$ and generally $\mathrm{D}_{1} 1 / 3$.

The main seal segment calculation parameters are: the depth of the water seal height $\mathrm{H}_{2}$ and $\mathrm{H}_{1}$, the total volume of water seal " $\mathrm{Va}$ ", seal segment block fluid plate. $\mathrm{H}_{1}$ seal depth is determined by the consumer. When the seal deep enough, it would not achieve the effect of preventing tempering. When seal depth too deep, venting pneumatic pressure loss is too large, affecting the normal emissions. $\mathrm{H}_{1}$ seal depth is calculated as follows:

$$
H_{1}=\frac{\Delta P}{\rho_{3} g}
$$

$\rho 3$ water density, pressure $\triangle P$ for the consumer with a difference. But the depth of the water seal is a range of seal depth $\mathrm{H}_{1}$ calculation is a reference value.

The total volume $V a$ seal water inlet and tank size, and when a negative pressure caused by the upstream tank seal water backflow into the tank inlet pipe, the total amount of seal water $V a_{\min }$ must ensure full three-meter main channel. In order to prevent negative pressure air into the upper reaches of the pipeline, the total amount of water $V a_{\max }$ seal plate is determined by the height and the water block fluid flow, the height of the water seal by the level gauge to monitor, when low starting pay, drainage time high.

Height $\mathrm{H}_{2}$ seal segment block design was based on board are: $S_{1}$ exhaust passage sectional area should be larger than the seal liquid separation tank gas inlet crosssectional area $\mathrm{S}_{2}$, highly liquid seal section roof panels above the water covers at least $0.2 \mathrm{~m}$ [11].

\subsection{Heating calculation}

Due to the low temperature in winter, the use of seal dispensing cans, tank temperature may reach well below zero degree. It may cause clogging pipes freeze. So it needs an installation of steam heat tracing and insulation which ensure safe operation of equipment.

Steam heating in the form of the current project is the application of more steam coil heating. Steam coil heating is divided into outer and inner heating with heat: where external heating steam pipe wrapped in tanks outside, relying on the heat pipe steam heating tank and seal water. While compensating for heat loss of the tank, internal heating steam pipe is fixed to the bottom of the tank body. By the release of all the heat of the steam used to heat the water seal, seal water directly supplemental heat dissipation. Two heating mode compared with thermal heat transfer within the high efficiency, small steam consumption, than the outer heating savings of $10 \%-25 \%$ the amount of steam [12]. But convenient external heating maintenance and suitable for corrosive torch gas system, it is widely used in the petrochemical field. Hot diameter calculation using external heating with the following: 


$$
d=\frac{K\left(t-t_{a}\right)}{\left(\frac{1}{2 \lambda} \ln \frac{D_{0}}{D_{i}}+\frac{1}{\alpha D_{i}}+\alpha D_{0}\right) \bullet \alpha_{t}\left(t_{s t}-t\right)}
$$

$t$ : Tank body sealing water temperature, ${ }^{\circ} \mathrm{C}$;

$t_{\mathrm{a}}$ : Ambient temperature, ${ }^{\circ} \mathrm{C}$;

$t_{\mathrm{st}}$ : Heating steam temperature, ${ }^{\circ} \mathrm{C}$;

$\lambda$ : For the insulation material thermal conductivity, $\mathrm{W} / \mathrm{mk}$; $d_{0}$ and $d_{\mathrm{i}}$ : Outer insulation diameter, inside diameter, $\mathrm{m}$;

$\alpha$ : Insulation outer surface heat transfer coefficient of air, $W / m^{2} k$;

$\alpha_{\mathrm{t}}$ : With heat pipe insulation into the space heat transfer coefficient, $W / m^{2} k$.

\section{Summary}

Based on the above analysis and calculation, through detailed design, and innovation of this structure applied after a coal chemical flare system is running with a good device performance and system security as well as stability. It has a good sense for the promotion of similar torch in VOCs prevision.

This design results are ideally suited for application in the port LNG/LPG or petrochemical tank atmospheric environmental engineering. Its advantage was as follows:

1. With respect to the sub-tank and water sealing split design, seal liquid separation tank integrated structure on the one hand to apply to such coal chemical torch, on the other hand can reduce equipment costs by $10 \%-15 \%$.

2. The sub-tank seal structure parameter design and dispensing tanks, water sealing design basically the same principle. Accounting retaining fluid plate height and other parameters, it needs to increase the length of the seal.

3. The seal liquid separation tank steam heating should be given priority outside heating. And engineering methods were commonly used in the outer coil steam heat tracing.

\section{Acknowledgement}

This work was supported by the Research of VOCs emissions inventory and reuse technology in loading and unloading crude oil in water transport (TKS140218).

\section{REFERENCES}

[1] F. Wei, J.J. Yao. Petroleum Refinery Engineering, 33, $61(2014)$

[2] G.M. Zhao. Petrochemical and Environment Protection Technology, 30, 1 (2014)

[3] Q.H. Meng. Petrochemical Safety and Environmental Protection Technology, 30, 7 (2014)

[4] F.M. Luo. Chemical Engineering Design, 23, 12 (2013)

[5] L.B. Li, Z.S. Liu, X.C. Fang. Modern Petrochemical Industry, 226, 4 (2013)

[6] Q. Huang, M.D. Chen, S.B Shen. Modern Petrochemical Industry, 35, 135 (2015)

[7] C.H. Hou. Environmental Protection Science, 34, 108 (2008)
[8] H.W. Chen, B. Yang. Journal of North China Electric Power University, 34, 60 (2007)

[9] Y.Q. Xie, J.L. Luo. Chemical Engineering Design Communications, 41, 53 (2015)

[10]W. Xue. Energy Saving and Environmental Protection, 24, 23 (2015)

[11]Z. Pan. J. China Coatings, 30, 23 (2015)

[12]N. Li, W. Guo, Y.G. Nong, W.F. Zhao. Science \& Technology Information, 14, 120 (2015) 